BULLETIN (New Series) OF THE

AMERICAN MATHEMATICAL SOCIETY

Volume 40, Number 1, Page 1

S 0273-0979(02)00973-4

Article electronically published on October 16, 2002

\title{
EDITOR'S COMMENT
}

\author{
DONALD G. SAARI
}

During the 1900 ICM, David Hilbert established a precedent by spelling out mathematical challenges for the coming century. Not as well known was another symposium held four years later in St. Louis, Missouri, as part of the U.S. centennial celebration of the Louisiana Purchase. During this 1904 gathering, Poincaré and others outlined still other mathematical challenges; some of these issues emphasized emerging connections between mathematics and physics, including the then new and perplexing theme called "relativity". Translations of both Hilbert's problems and Poincaré's lecture were published in the Bulletin almost a century ago; both have been republished in the Bulletin since January 2000 as part of this journal's recognition of the new millennium.

The change of the millennium and the centennial anniversary of Hilbert's lecture provided another natural juncture for a careful reflection on where we, as a field, have been, where we are going, and what new challenges we are facing. The purpose of "Mathematical Challenges of the 21st Century" was to achieve this goal. Five years in the making, the meeting was organized by Felix Browder, who assembled an illustrious group of mathematicians - in which eight of the thirty speakers were Field's winners - to meet this challenge. Beyond setting general directions for mathematics, there was an emphasis on the extraordinary connections developing between mathematics and related sciences. This meeting took place at UCLA during August 2000.

Because the theme of "Mathematical Challenges" coincides with the goals of the Bulletin, it seemed most appropriate for us to publish some of the written versions of the talks. We hope you enjoy them!

Department of Mathematics, University of California, Irvine, Irvine, California 92697-3875

E-mail address: dsaari@math.uci.edu 